\title{
OBSTRUÇÃO INTRALUMINAL DE COLON MENOR POR FITOBENZOAR EM UMA RECEPTORA DE EMBRIÃO
}

\author{
FREITAS, Fernanda Coutinho ${ }^{1}$ \\ D’AURIA, Eliana ${ }^{2}$ \\ MORAES, Angélica Trazzi Bento ${ }^{3}$ \\ AGOSTINHO, Juliana Maria Avanci ${ }^{4}$ \\ LATARO, Rita Aparecida ${ }^{1}$
}

\begin{abstract}
RESUMO: A síndrome cólica é identificada como uma síndrome complexa e seu reconhecimento precoce e diferenciação apurada é muito importante para estabelecer a abordagem adequada. A síndrome cólica por compactação descreve uma obstrução luminal por massas desidratadas de ingesta, ocasionando uma obstrução simples do lúmen intestinal, que geralmente, não resulta em necrose ou isquemia, sendo apontada como a principal causa de cólica nos eqüinos. Vários agentes etiológicos estão envolvidos, mas a etiopatogenia da formação das compactações permanece incerta. Nem sempre a terapia clínica é eficaz nas obstruções intraluminais, sendo a correção cirúrgica necessária para a resolução do problema, como no caso a seguir, envolvendo uma receptora de embrião.
\end{abstract}

Palavas-chave: Equino. Fitobenzoar. Prenhez.

\section{INTRALUMINAL OBSTRUCTION PHYITOBEZOAR OF COLON BY SMAL IN A RECIPIENT OF EMBRYO}

SUMMARY: The colic syndrome is identified as a syndrome and its early detection and accurate differentiation is very important to establish the appropriate approach. The colic syndrome describes a luminal obstruction by masses of dehydrated food intake, causing a simple obstruction of the intestinal lumen, which usually does not result in necrosis or ischemia, and appointed as the main cause of colic in horses. Several etiologic agents are involved, but the pathogenesis of the formation of compaction remains uncertain. Not always the clinical therapy is effective in intraluminal obstructions, surgical repair necessary to solve the problem, as in the following case, involving a recipient mare.

Keywords: Equine. Phytobezoar. Pregnancy.

\section{INTRODUÇÃO}

A síndrome cólica reflete em óbitos de muitos equinos ao longo da história. As pesquisas iniciais sobre a cólica baseavam-se somente em achados de necropsia ou na

\footnotetext{
1 Médica Veterinária do Hospital Veterinário da Fafram- Ituverava-SP.

${ }^{2}$ Professora Msc. do Curso de Medicina Veterinária da Fafram- Ituverava-SP.

${ }^{3}$ Professora Dr ${ }^{\mathrm{a}}$. do Curso de Medicina Veterinária da Fafram- Ituverava-SP.

${ }^{4}$ Médica Veterinária Aprimoranda do Hospital Veterinário da Fafram- Ituverava-SP.
} 
resposta ao tratamento utilizado (WHITE II, 2006). É identificada como uma síndrome complexa e seu reconhecimento precoce e diferenciação apurada são fatores importantes para estabelecer a abordagem adequada (REED; BAYLY, 2000).

Os equinos apresentam peculiaridades anatômicas em seu aparelho digestório, fatores os quais os predispõem a alterações morfofisiológicas graves, responsáveis por ocasionar dores abdominais, sendo esta conhecida genericamente como síndrome cólica (GODOY; TEIXEIRA NETO, 2007).

Vários fatores são apontados como fatores de risco e, dentre eles estão, mudanças no tipo, na quantidade e na qualidade do alimento (GONÇALVES et al., 2002), idade, raça (MEHDI; MOHAMMAD, 2006), atividade física (TRAUB-DARGATZ et al.,2001); restrição de acesso ao pasto (HUDSON et al., 2001) e histórico de cólicas anteriores e de cirurgias abdominais (COHEN et al., 1995).

Os distúrbios podem ser gástricos ou intestinais, obstrutivos ou não, ocorrendo ou não um estrangulamento vascular (WHITE II, 2006).

A síndrome cólica por compactação descreve uma obstrução luminal por massas desidratadas de ingesta (LOPES, 2009), ocasionando uma obstrução simples do lúmen intestinal, que geralmente, não resulta em necrose ou isquemia, sendo apontada como a principal causa de cólica nos eqüinos (WHITE, 1998; PLUMMER, 2009). Embora as compactações sejam diagnosticadas frequentemente na flexura pélvica, elas podem ocorrer em qualquer segmento do trato gastrintestinal (FERREIRA et al., 2008a). Vários agentes etiológicos estão envolvidos, mas a etiopatogenia da formação das compactações permanece incerta.

Alterações de manejo e dieta, alteração da motilidade do trato gastrintestinal (NEWTON, 1998; MELO et al., 2007a), afecções odontológicas (SCHLIPH ; BAXTER, 1992), forragem com alto teor de lignina, deficiência de secreção do trato gastrintestinal, restrição ao exercício, acesso restrito à água fresca, paralisia de terminações nervosas (WHITE, 1998), idade avançada (DABAREINER ; WHITE，1995) e condições climáticas têm sido relatadas como fatores de risco (COHEN et al., 1995).

Os mecanismos associados ao acúmulo de ingesta no intestino grosso permanecem incertos, entretanto, a alteração do fluxo da ingesta e/ou na secreção/absorção de fluido pelo trato gastrintestinal parecem ser os principais responsáveis (JONES et al., 2000).

A compactação do cólon menor é mais frequente no outono e esta predileção sazonal pode está relacionada com a modificação na dieta. Equinos idosos podem ser predispostos à 
compactação de cólon menor devido às afecções odontológicas refletindo na função gastrintestinal (SCHUMACHER ; MAIR, 2002).

O equino acometido por compactação apresenta sinais vitais relativamente normais. A dor é normalmente moderada e frequentemente intermitente, em alguns casos os sinais incluem olhar para o flanco, cavar, deitar e rolar. A frequência cardíaca pode estar levemente aumentada (40-60 bpm) estando esta relacionada à hipovolemia e grau de dor (FERREIRA et al., 2008a). A auscultação abdominal revela diminuição dos sons intestinais e a motilidade progressiva quase sempre está ausente, embora algumas compactações do cólon maior provoquem aumento nos borborigmos os quais são intermitentes e concomitantes com a dor abdominal. A produção fecal apresenta redução, e as fezes são duras, ressecadas e cobertas de muco (FERREIRA et al., 2008c).

Objetiva-se com o tratamento clínico hidratar ou lubrificar o material suficientemente para permitir que o intestino faça com que a massa diminua de tamanho e então possa ser removida pela motilidade gastrintestinal normal (WHITE; DABAREINER, 1997). A grande porcentagem das compactações respondem ao tratamento clínico visando a restrição alimentar, controle da dor, amolecimento e hidratação da ingesta colônica, manutenção da hidratação e redução dos espasmos da musculatura intestinal na região afetada (FERREIRA et al., 2008a). Caso a compactação não se desfaça e o quadro clínico não se reverta com a terapia médica, a laparotomia exploratória é indicada.

Os casos de compactação com evolução de vários dias podem levar à necrose do segmento entérico comprometido e seu rompimento no período pré ou trans-operatório, podendo acarretar o óbito do animal (THOMASSIAN, 2005).

\section{RELATO DE CASO}

Este artigo descreve o caso de uma égua da raça Mangalarga Machador, de 10 anos, pesando $300 \mathrm{~kg}$, utilizada como receptora de embrião, sendo está transferida de propriedade. Após 6 dias de estadia na nova propriedade, esta foi encontrada deitada na baia demonstrando sinais de desconforto abdominal. Ao exame clínico apresentou 37 bpm; 28mpm; mucosas normocoradas; diminuição dos borborigmos intestinais; temperatura $38,7^{\circ} \mathrm{C}$; a sondagem nasogástrica foi produtiva, sendo compatível com compactação gástrica; na palpação transretal foi observado distensão e compactação de cólon esquerdo evidenciada pela presença de uma massa localizada no quadrante ventral esquerdo caudal do abdômen e compactação de cólon menor. Na paracentese obteve-se líquido peritoneal amarelo citríno. A égua foi 
submetida à fluidoterapia intensiva via enteral e parenteral. Lavagens gástricas foram realizadas, sendo administrado 700ml de leite de magnésio e 2 litros de óleo mineral. Recebeu como terapia analgésica flunixin meglumine $(1,1 \mathrm{mg} / \mathrm{kg}, \mathrm{IV}) . \mathrm{O}$ animal foi acompanhado no decorrer do dia, apresentando deterioração do quadro clínico e um deslocamento médio lateral direito do cólon esquerdo seguido de timpanismo do ceco, sendo visível o abaulamento do flanco direito.

A laparotomia mediana ventral foi indicada, sendo realizada após anestesia geral inalatória. Foi realizada a exploração sistemática de toda cavidade abdominal, aonde foi constatado uma compactação do cólon dorsal esquerdo e direito, sendo este submetido à celiotomia e enterorrafia, realizada em dois planos de sutura, simples contínuo e cushing, utilizando o vicryl $n^{\circ} 0$. Havia também uma obstrução intraluminal do terço médio do cólon menor (Figura 1), sendo este incidido sobre a tênia antimesentérica, obtendo-se uma massa fibrosa desidratada e endurecida de capim verde, sendo compatível com fitobenzoar. A enterorrafia foi realizada em dois planos de sutura, simples contínuo e cushing, com vicryl $\mathrm{n}^{\circ} 0$.

A égua recebeu no pós-operatório penicilina procaína (40.000 UI, bid, por 10 dias); gentamicina $(2 \mathrm{mg} / \mathrm{kg}$, bid, por 3 dias); dimetil sulfóxido ( $1 \mathrm{~g} / \mathrm{kg}$, bid, por 3 dias); flunixin meglumine (1,1 mg/kg, sid, por 5 dias); ranitidina ( $2 \mathrm{mg} \mathrm{kg}$, tid, por 10 dias) e curativos diários realizados com iodo povidine tópico até a retirada dos pontos cirúrgicos, após 10 dias.

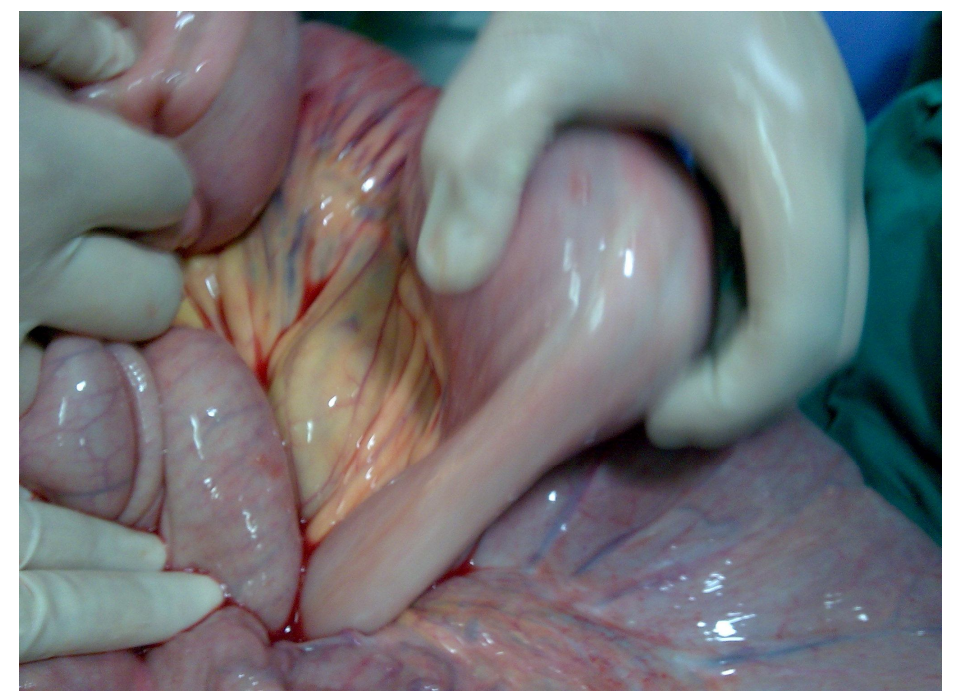

Figura 1- Presença de fitobenzoar no terço médio do cólon menor. 


\section{RESULTADOS E DISCUSSÃO}

Vários fatores contribuíram para a compactação do cólon dorsal e obstrução por fitobenzoar no cólon menor neste caso como: a alteração da dieta ( GONÇALVES et al., 2002), presença de arestas dentárias e má oclusão, ocasionadas pelo fatos idade (MEHDI; MOHAMMAD, 2006), e fatores associados também à mudança climática sofrida pelo animal (COHEN et al., 1995).

Não foi evidenciada nenhuma complicação pós-operatória, retornando a sua atividade normal de receptora após 2 meses da laparotomia exploratória.

Durante o período de estação de monta a égua foi utilizada como receptora, apresentando ciclos normais, respondendo aos tratamentos hormonais utilizados para ovulação. No entanto, não foi necessária a sua utilização para transferência de embrião.

\section{CONCLUSÃO}

A obstrução intraluminal em equinos representa um desafio terapêutico, em alguns casos, na clínica de equinos. Dependendo do tempo de evolução, do segmento intestinal envolvido e da terapia empregada. No entanto, nem sempre a terapia clínica é eficaz nas obstruções intraluminais, sendo a correção cirúrgica necessária para a resolução do problema, conforme descrito neste relato.

O procedimento cirúrgico viabilizou o retorno do animal a sua atividade reprodutiva. No término da estação de monta, esta foi coberta por monta natural após ciclar naturalmente, apresentando prenhez positiva evidenciada no exame ultrassonográfico, após treze dias de ovulação.

\section{REFERÊNCIAS}

COHEN, N.D. et al. Case-control study of the association between various management factors and development of colic in horses. Journal of American Veterinary Medical Association, v.206, n.5, p.667-673, 1995.

DABAREINER, R.M.; WHITE, N.A. 1995. Large colon impaction in horses:147 cases (1985-1991). J. Am. Vet. Med. Assoc. 206:679- 685. 
FERREIRA, C.et al. 2008a. Compactações do trato gastrintestinal em equinos: achados clínicos de 64 casos. In: CONFERÊNCIA SUL-AMERICANA DE MEDICINA VETERINÁRIA, 8. Anais... Rio de Janeiro, RJ. CD-ROM.

GODOY, R.F.; TEIXEIRA NETO, A.R. Cólica em eqüinos. In: RIET-CORREA, F.et al. (eds). Doenças de ruminantes e equídeos. v.2. Santa Maria: Palotti, 2007, p.571-621.

GONÇALVES, S. et al. Risk factors associated with colic in horses. Veterinary Research, v.33, n.6, p.641-652. 2002.

JONES, S.L.; SNYDER, J.R.; SPIER, S.J. Exame dos distúrbios do intestino grosso, p. 563567. In: REED S.M.; BAYLY W.M. Medicina interna equina. Rio de Janeiro: Guanabara Koogan, 2000.

LOPES, M. A. et al, Treatment of larg colon impaction. AAEP proceedings... v. 45, 1999.

MEHDI, S.; MOHAMMAD, V. A farm-based prospective study of equine colic incidence and associated risk factors. Journal of Equine Veterinary Science, v.26, n.4, p.171-174, 2006.

MELO, U.P., FERREIRA, C.; PALHARES, M.S. . Doenças gastrintestinais em potros: etiologia e tratamento. Ciênc. An. Bras. v.8, p.733-744, 2007.

MELO, U.P.; PALHARES, M.S.; FERREIRA, C. Íleo adinâmico em equinos: fisiopatologia e tratamento. Arq. Ciênc. Vet. Zool. UNIPAR, v.10, p.49-58, 2007c.

NEWTON, S.A. Three cases of pelvic flexure impaction in the horse. Equine Vet. Educ. v.10, p.284-290, 1998.

PLUMMER, A.E. Impactions of the small and large intestines. Vet. Clin. N. Am. Equine Pract. v.25, p.317-327, 2009.

REED, S.M; BAYLY, W.M. Medicina interna equina, Rio de Janeiro: Guanabara Koogan, 2000, p. 565.

SCHUMACHER, J.; MAIR, T.S. Small colon obstructions in the mature horse. Equine Vet. Educ. v.14, p.19-28, 2002.

TRAUB-DARGATZ, J.L. et al. Estimate of the national incidence of and operation-level risk factors for colic among horses in the United States, spring 1998 to spring 1999. Journal of American Veterinary Medical Association, v.219, n.1, p.67-71, 2001.

WHITE II, N.A. 1998. Large colon impaction. Equine Vet. Educ. 10:291-293.

WHITE II, N.A. Equine Colic. AAEP Proceedings... v.52, 2006, p.109-174. 